\title{
Selection and utilization of spermatozoa in the reproductive tract of the female zebra finch Taeniopygia guttata
}

\author{
T. R. Birkhead, E. J. Pellatt and F. Fletcher \\ Department of Animal and Plant Sciences, PO Box 601, The University, Sheffield S10 2UQ, UK
}

\begin{abstract}
The numbers and proportion of spermatozoa reaching different parts of the female reproductive tract after a single natural insemination were investigated in zebra finches Taeniopygia guttata. The number of spermatozoa transferred during a single, natural copulation was estimated by comparing the number of spermatozoa in the seminal glomera of males that had performed a single copulation with control males. The mean number of spermatozoa per ejaculate was $5.8 \times 10^{6} \pm 1.80 \times 10^{6} \mathrm{SEM}$. The mean number of spermatozoa stored in the sperm storage tubules in the uterovaginal junction following a single, natural insemination was $6027 \pm 1874,0.104 \%$ of those inseminated. The mean number of spermatozoa reaching the infundibulum and trapped on the perivitelline layer of all eggs of the clutch after a single copulation was $45.6 \pm 9.18$ and a further 36 penetrated the perivitelline layer of the ovum, i.e. 82 in total (1.4\% of the spermatozoa in the sperm storage tubules and $0.001 \%$ of spermatozoa in the ejaculate). Female zebra finches that completed a natural breeding cycle with a mean of 12 copulations had $404 \pm 111$ spermatozoa trapped on the perivitelline layer of all eggs of the clutch, and an estimated further 173 spermatozoa penetrated the perivitelline layer. A smaller proportion of spermatozoa was trapped on the perivitelline layer of zebra finch eggs, than in chicken or turkey eggs.
\end{abstract}

\section{Introduction}

The competition between spermatozoa from different males to fertilize the eggs of a single female (Parker, 1970) is now recognized as being an important part of the reproductive biology of many species (Smith, 1984), including mammals (Ginsberg and Huck, 1989; Møller and Birkhead, 1989) and birds (Birkhead and Møller, 1992a). The outcome of sperm competition can be either a 'raffle', in which the likelihood of paternity is proportional to the number of spermatozoa from each copulating male, or there may be order effects in which the first or, more usually, the last male fertilizes a disproportionate number of eggs (Birkhead and Hunter 1990). Both processes occur in birds, although at different times. If a female is inseminated by two males in rapid succession, the 'raffle' system predominates (Martin et al., 1974; Cheng et al., 1983), but if the interval between inseminations is 4 or more hours then 'last-male' sperm precedence appears to be the rule (Birkhead, 1988; Birkhead and Møller, 1992a). There has been considerable speculation about the physiological mechanisms responsible for these processes (Compton et al., 1978; Lessells and Birkhead, 1990), but they remain poorly understood.

The outcome of sperm competition has traditionally been assumed to be under male control, with females acting as passive receptacles (see, for example, Compton et al., 1978). However, more recently it has been proposed, first, that females may exert some control over the paternity of their offspring,

Received 29 January 1993. either before copulation, through behavioural means, or after insemination, using anatomical or physiological mechanisms; and second, that sexual selection acts on both sexes independently, resulting in the coevolution of male and female traits (Birkhead et al, 1993). One way in which females might control paternity is through the selection of spermatozoa within their reproductive tract (Wishart and Steele, 1990). After copulation, female birds store spermatozoa in sperm storage tubules located at the uterovaginal junction (Bobr et al., 1964).

After release from the sperm storage tubules, spermatozoa are transported to the infundibulum, the site of fertilization. Fertilization occurs within approximately $30 \mathrm{~min}$ after ovulation. Spermatozoa in the infundibulum at the time of ovulation become trapped in the perivitelline layer of the ovum and can subsequently be detected once the egg is laid. In many species, there is a dramatic reduction in the numbers of spermatozoa between insemination and the site of fertilization (Bedford, 1970; Suarez et al., 1990), providing females with the opportunity to select spermatozoa, either from within single ejaculates or between those from different males (e.g. Madsen et al, 1992). Although this reduction in numbers of spermatozoa is well documented in eutherian mammals (Suarez et al., 1990) and marsupials (Taggart and Temple-Smith, 1991), this is not the case in birds. The only information for birds comes from studies of domestic poultry, using artificial insemination (Wishart, 1987, 1988; Brillard and Antoine, 1990; Brillard and Bakst, 1990). Studies which use artificial insemination may not provide the most meaningful information in terms of sperm selection, since it is possible that artificial insemination removes any control that females might have over the uptake or selection of spermatozoa.

Downloaded from Bioscientifica.com at 04/26/2023 09:35:52AM 
The aim of the present study was therefore to examine the reduction in number of spermatozoa between ejaculation and the site of fertilization following natural copulation in a passerine bird, the zebra finch Taeniopygia guttata. The zebra finch is a small (12-15 g) colonial passerine, which in the wild in Australia is an opportunistic breeder (Sossinka 1980a, b). Although captive zebra finches in Britain are now considered to be domesticated, they still retain many of the behavioural characteristics of wild birds (Sossinka, 1982; Birkhead et al., 1989). The reproductive biology, and sperm competition in particular, of this species has been studied in detail, both in captivity and the wild (Birkhead et al., 1988, 1989; Birkhead and Fletcher, 1992).

\section{Material and Methods}

\section{Animals}

The zebra finches used in this study were wild-type domesticated birds from a colony maintained at the University of Sheffield since 1985. The birds were provided with food and water ad libitum and maintained on a $14 \mathrm{~h}$ light: $10 \mathrm{~h}$ dark cycle, as described elsewhere (Birkhead et al., 1989).

\section{Number of spermatozoa in ejaculate}

Little is known of the number of spermatozoa transferred during natural copulation in birds, even in poultry the reproductive biology of which has been extensively examined (Johnson, 1986; Van Krey, 1990). The collection of natural ejaculates from birds is technically difficult. The number of spermatozoa transferred during copulation was determined by comparing the number of spermatozoa in the seminal glomera of males (see Wolfson, 1954) that had inseminated a female with control males that had not. The seminal glomera are paired storage sites formed from the coiled, caudal end of the ductus deferens, adjacent to the cloaca. A paired experimental design was used: experimental and control males were littermates and were simultaneously paired with the same female (each male was placed in a cage on either side of a female, but separated from the female by a wire screen in such a way that the female could see and interact with each male, but the males were visually isolated). The aim of using littermates was to reduce the variance due to genetic differences between individuals and the aim of using the same female was to control for possible differences in female attractiveness. Four days after pairing which male would be experimental and which would be the control was chosen on a random basis. Experimental birds were then allowed to perform a single copulation with the female. A vaginal smear was taken from the female (see Birkhead, 1991) to check that spermatozoa had been transferred during copulation. An interval of 4 days between pairing and copulation was chosen because this is the mean interval between pairing and the peak copulation frequency (Birkhead et al., 1989). Immediately after the experimental bird had copulated, both males were killed by cervical dislocation. The birds were weighed (to the nearest $0.1 \mathrm{~g}$ ) and testes and seminal glomera were removed. The combined mass (to the nearest $0.0001 \mathrm{~g}$ ) of both testes and both seminal glomera were recorded using a
Mettler AE 160 electronic balance (Mettler, Toledo). Spermatozoa were extruded from the seminal glomera and any remaining spermatozoa were released by macerating the tissue in a known volume of phosphate-buffered saline (PBS). The number of spermatozoa was counted in an Improved Neubauer chamber. The difference between the control and experimental group was used to estimate the number of spermatozoa in a single, natural ejaculate from rested males. A total of fifteen pairs of males was used in this part of the study.

\section{Number of spermatozoa in female sperm storage tubules}

Six females were allowed to copulate once with a male. Twenty-four hours later the birds were killed by cervical dislocation and the oviducts dissected out as described by Birkhead and Hunter (1990b) and the number of spermatozoa in the sperm storage tubules counted. Briefly, we removed five randomly chosen primary mucosal folds from the uterovaginal junction and counted the number of spermatozoa in a total of 100 sperm storage tubules in each female using light microscopy with unfixed, unstained tissue. The mean number of sperm storage tubules per female was found to be 1499 by Birkhead and Hunter (1990b). The total sperm population in the sperm storage tubules was therefore estimated by multiplying the mean number per tubule by 1499 .

Four females that had been paired and allowed to copulate ad libitum were examined $72 \mathrm{~h}$ after laying the final egg to determine whether any spermatozoa remained in the sperm storage tubules after clutch completion. For each bird, the contents of 100 sperm storage tubules were examined as described above.

\section{Number of spermatozoa trapped on and penetrating the perivitelline layer}

The technique established by Wishart (1987) was used to count spermatozoa on the perivitelline layers of zebra finch eggs. Newly laid eggs were opened, the yolk and albumen separated, and the yolk cut in half. The adherent yolk was removed from the perivitelline layer by gentle shaking in PBS and the two halves laid separately onto a microscope slide. Spermatozoa on the perivitelline layer were stained using Hoechst dye 33342. The number of spermatozoa on all eggs of five clutches from five different females following a single insemination was counted, as well as the number of spermatozoa on all eggs of one clutch of 11 different pairs of birds (caged singly) that had been allowed to copulate ad libitum. Finally, we obtained the same data for ten pairs of first generation offspring of wild-caught zebra finches, to check that the results from domesticated birds were representative.

There are several methods, which involve staining the perivitelline layer, for visualizing the holes made in the perivitelline layer by spermatozoa (Bramwell and Howarth, 1992; G. J. Wishart, personal communication). However, in the present study we wanted to determine the relationship between the numbers of spermatozoa attached to the perivitelline layer and the number of holes in the same layers; dark field optics were therefore used to identify holes. The number of spermatozoa and holes in one or more fields (at magnifications of $\times 100$ to $\times 250$ ), at the germinal disc and on other parts of the layer for a single egg from ten different females were counted. The Downloaded from Bioscientifica.com at 04/26/2023 09:35:52AM 
Table 1. Comparison of control and experimental male zebra finches used to estimate numbers of spermatozoa in a single ejaculate

\begin{tabular}{|c|c|c|c|c|}
\hline Variable & $\begin{array}{c}\text { Control } \\
\text { mean } \pm \text { SEM }\end{array}$ & $\begin{array}{l}\text { Experimental } \\
\text { mean } \pm \text { SEM }\end{array}$ & $t$ & $P$ \\
\hline Body mass (g) & $15.40 \pm 0.399$ & $15.44 \pm 0.337$ & 0.07 & NS \\
\hline Testes mass (g) & $0.054 \pm 0.004$ & $0.055 \pm 0.004$ & 0.004 & NS \\
\hline Seminal glomera mass (g) & $0.006 \pm 0.0004$ & $0.005 \pm 0.001$ & 1.36 & NS \\
\hline $\begin{array}{l}\text { Number of spermatozoa }\left(\times 10^{6}\right) \text { in } \\
\text { seminal glomera }\end{array}$ & $10.03 \pm 1.80$ & $4.21 \pm 0.74$ & 5.58 & $<0.0001$ \\
\hline
\end{tabular}

All tests are paired $t$ tests with 14 d.f. NS: $P>0.05$.
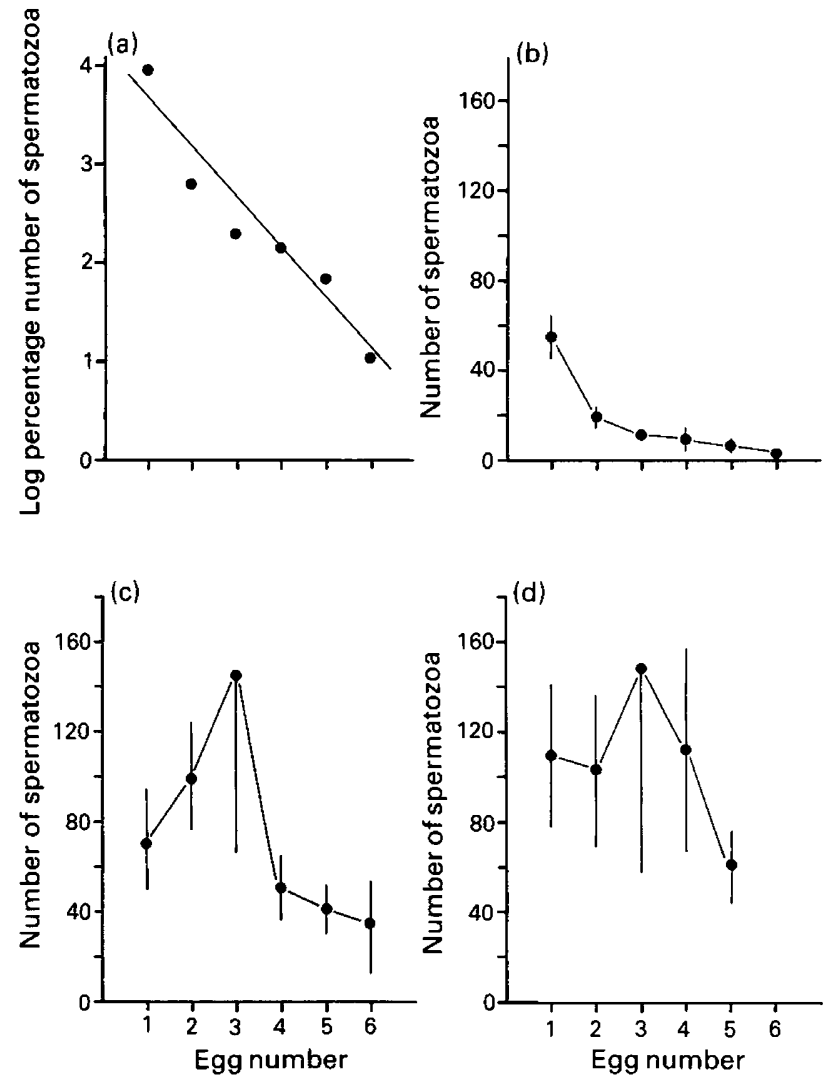

Fig. 1. (a) Relationship between log number of spermatozoa on the perivitelline layers and laying sequence following a single insemination in zebra finches 3-5 days before the first egg was laid. Data are for five pairs standardized by expressing number of spermatozoa on the entire clutch as a percentage. The relationship is significant $(r=-0.969$, 4 d.f., $P=0.0014$ ). (b) Relationship between number of spermatozoa on the perivitelline layers and laying sequence following a single insemination in zebra finches 3-5 days before the first egg was laid. Data are means \pm SEM for five pairs standardized by expressing number of spermatozoa on the entire clutch as a percentage. The relationship is significant $(r=-0.828,4$ d.f., $P<0.05)$, but the $r^{2}$ value is lower than that in (a). (c) Changes in number of spermatozoa on the perivitelline layers of eggs in 11 females allowed to copulate ad libitum. Values are means \pm SEM. Two-way ANOVA showed no effect of day $\left(F_{4,28}=0.705\right)$ or bird $\left(F_{7,32}=0.586\right)$, using data for eight pairs that each laid at least five eggs. (d) Changes in number of spermatozoa on the perivitelline layers of eggs in ten wild, female zebra finches in captivity allowed to copulate ad libitum. Values are means \pm SEM. There was no effect of bird, or day (ANOVA). density of spermatozoa and holes for both the germinal disc area and for the entire perivitelline layer were then calculated.

The presence of spermatozoa in albumen (see Bobr et al., 1964) was checked for in the following way. Ten eggs from four females with a mean of 58.40 spermatozoa \pm 14.24 SEM (range $8-158)$ on their perivitelline layers were used and $20 \mu \mathrm{l}$ of albumen from each egg (about $3 \%$ of the albumen in an egg) was spread thinly on a microscope slide and stained with Hoechst 33342. No spermatozoa were found.

\section{Statistical analysis}

All statistical tests were two-tailed. Means are presented \pm SEM.

\section{Results}

\section{Number of spermatozoa in ejaculates}

There were no significant differences between control and experimental males in body, testes, or seminal glomera mass (Table 1). The mean number of spermatozoa in the seminal glomera of control males $\left(10.03 \times 10^{6} \pm 1.80 \times 10^{6}\right.$ (range: $\left.1.98-26.3 \times 10^{6}\right)$ ) was significantly higher than in experimental males $\left(4.21 \times 10^{6} \pm 0.74 \times 10^{6}\right.$ (range: 0.08 to $\left.9.9 \times 10^{6}\right)$ : paired $t$ test, $t=5.58$, d.f. $=14, P<0.0001$ ). The difference between the numbers of spermatozoa in the seminal glomera of experimental and control males indicated that males are transferred $5.82 \times 10^{6} \pm 1.53 \times 10^{6}$ spermatozoa during a single copulation. This value is close to that predicted for a bird the size of a zebra finch derived from a comparative study in which numbers of spermatozoa were obtained from massage samples (Møller, 1988).

The log of the number of spermatozoa in the seminal glomera was significantly and positively associated with testes mass ( $r=$ $0.515,13$ d.f., $P<0.05)$ and with seminal glomera mass $(r=$ 0.713 , 13 d.f., $P<0.003)$, but not with body mass $(r=0.419$, 13 d.f.) for control males.

\section{Numbers of spermatozoa in female sperm storage tubules}

The mean number of spermatozoa in the sperm storage tubules following a single insemination from rested males was estimated as $6027 \pm 1874$ ( $n=6$ females). With a mean of $5.8 \times 10^{6}$ spermatozoa per ejaculate (see above), only $0.104 \%$ Downloaded from Bioscientifica.com at 04/26/2023 09:35:52AM 
Table 2. Numbers of spermatozoa reaching the site of fertilization in birds and mammals

\begin{tabular}{|c|c|c|c|c|}
\hline Class & Species & $\begin{array}{l}\text { Number of spermatozoa } \\
\text { inseminated }\left(\times 10^{6}\right)^{a}\end{array}$ & $\begin{array}{l}\text { Number of spermatozoa at } \\
\text { site of fertilization (\%) }\end{array}$ & Reference \\
\hline \multirow[t]{3}{*}{ Birds } & Turkey & 250 & $136000(0.054)$ & $\begin{array}{l}\text { Brillard and Bakst (1990) } \\
\text { J.P. Brillard } \\
\text { (Personal communication) }\end{array}$ \\
\hline & Chicken & 100 & $105000(0.105)$ & Brillard and Antoine (1990) \\
\hline & Zebra finch & 5.8 & $45(0.00078)$ & Present study \\
\hline \multirow[t]{6}{*}{ Mammals } & Mouse & 50 & $<5(0.00001)$ & Suarez et al. (1990) \\
\hline & Rat & 58 & $2(0.0000034)$ & Suarez et al. (1990) \\
\hline & Hamster & 100 & $2(0.000000002)$ & Suarez et al. (1990) \\
\hline & Rabbit & 280 & $118(0.000042)$ & Suarez et al. (1990) \\
\hline & Sheep & 1000 & $<26(0.0000026)$ & Suarez et al. (1990) \\
\hline & Cow & 3000 & $<10(0.00000033)$ & Suarez et al. (1990) \\
\hline
\end{tabular}

'All data on numbers of spermatozoa inseminated refer to artificial insemination except for the zebra finch, where natural copulation was used. The site of fertilization refers to spermatozoa on the perivitelline layer of all eggs of the clutch in birds (using data from Wishart (1988) for turkey and chicken, and refers to the ampulla in mammals).
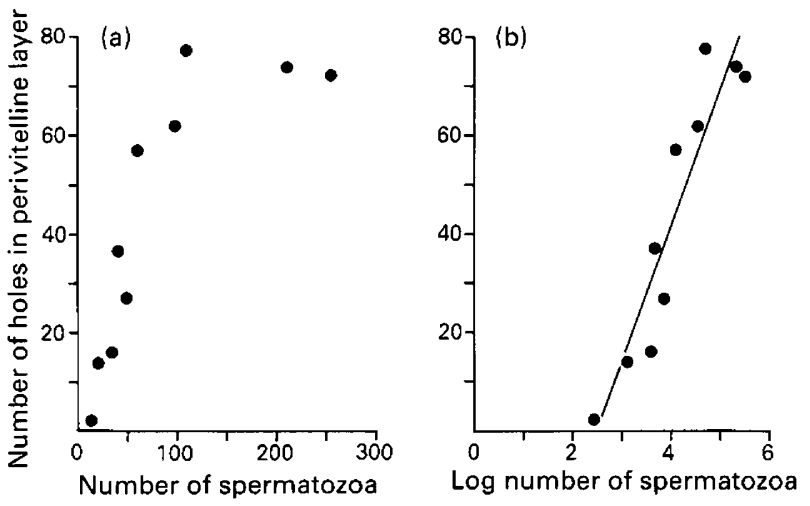

Fig. 2. (a) Relationship between number of spermatozoa trapped on the perivitelline layer and the number of spermatozoa penetrating the perivitelline layer (as detected by the total number of holes in the perivitelline layer) of ovum from zebra finches. (b) Relationship between $\log$ numbers of spermatozoa and the total number of holes in the perivitelline layer $(r=0.927,8$ d.f., $P<0.001 ; y=27.16 x-$ 67.35).

of spermatozoa from the ejaculate were therefore present in the sperm storage tubules $24 \mathrm{~h}$ later. Some spermatozoa were observed in the vagina $24 \mathrm{~h}$ after insemination, and in other females spermatozoa had been ejected with faeces. However, even with careful flushing of the oviduct few spermatozoa were found elsewhere in the female reproductive tract.

\section{Number of spermatozoa on the perivitelline layer of the ovum}

The mean number of spermatozoa counted on the entire perivitelline layer of complete clutches following a single insemination was $45.60 \pm 9.18$ ( $n=5$ females), or $0.756 \%$ of the number in the sperm storage tubules, and $0.00078 \%$ of those inseminated. The mean clutch size in the five females was 5.80 eggs (range: $5-7$ ). For these females, the single insemination took place on day $-4.4 \pm 0.40$ (range: -3 to -5 ) (where day $0=$ the day on which the first egg of the clutch is laid). There was a significant decline in the number of spermatozoa on successive eggs, and a semi-log plot (Fig. Ia) gave a higher correlation coefficient $\left(r^{2}=0.969, P<0.0014\right)$ than the raw data $\left(r^{2}=0.828\right)$ (Fig. Ib), indicating that spermatozoa were released from the storage tubules at a constant rate, as Wishart (1987) recorded for chickens. The instantaneous rate of decline in number of spermatozoa following a single insemination (see Fig. Ia) was determined by calculating the relationship between $\log _{e}$ of the number of spermatozoa on perivitelline layers and time $(\mathrm{h})$ for each pair, and then calculating the mean slope for the five females. The instantaneous loss rate: 0.026 spermatozoa $h^{-1} \pm 0.007$ for zebra finches was higher than for Japanese quails (0.015 spermatozoa $h^{-1} \pm 0.002$ (Birkhead and Fletcher in press)), chickens (0.013 spermatozoa $\left.h^{-1} \pm 0.001\right)$ and turkeys (0.003 spermatozoa $h^{-1} \pm 0.0003$ ) (Wishart, 1988).

Despite the relatively small numbers of spermatozoa on the perivitelline layers of females that had been inseminated only once (Fig. 1b), previous studies with zebra finches have shown that a single insemination is sufficient for fertilization of an entire clutch (Birkhead et al., 1989). Under natural conditions, however, zebra finch pairs copulate several times for each clutch of eggs (Birkhead et al., 1989). We, therefore, examined the total number of spermatozoa on entire clutches for eleven single pairs that had been maintained separately and allowed to copulate ad libitum during a natural breeding cycle. The mean number of spermatozoa per clutch was $404 \pm 111$ (range: 601469), which is close to that expected: zebra finches copulate about 12 times for each clutch, but on average only $67 \%$ of these result in spermatozoa transfer (Birkhead et al, 1989), therefore 12 (copulations) $\times 0.67$ (success) $\times 45.6$ (number of spermatozoa on perivitelline layers from single insemination) $=366$ spermatozoa expected on perivitelline layers.

Our results, using natural copulations, are broadly similar to those obtained for domestic fowls and turkeys (see above) using artificial insemination. The pattern of spermatozoa reduction in the three bird species is summarized in Table 2 . 

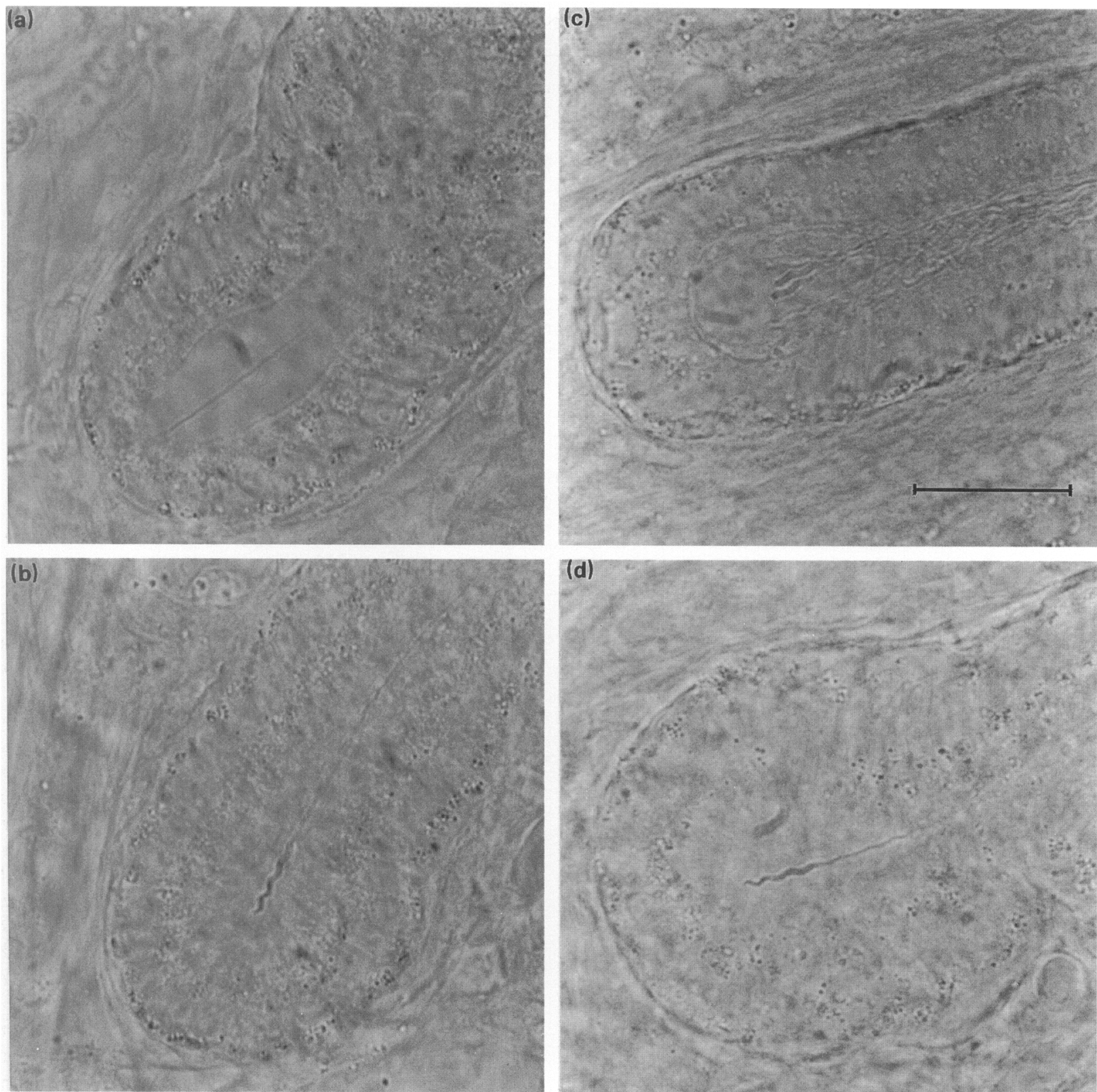

Fig. 3. Spermatozoa in the distal end of a sperm storage tubule of a female zebra finch are shown after completion of the clutch. (a) Single spermatozoon without head; (b) single normal spermatozoon; (c) spermatozoa without acrosome, and (d) single normal spermatozoon. Scale bar represents $20 \mu \mathrm{m}$.

The pattern of numbers of spermatozoa on successive eggs under natural conditions (Fig. 1c) differed from that of single inseminations, showing a peak around the middle of the clutch. However, a two-way ANOVA revealed no significant effect of either day or bird on number of spermatozoa (see Fig. Ic). The observed pattern differed from that in Fig. Ib, presumably because copulations sometimes occur during the egg-laying period (Birkhead et al, 1989), when spermatozoa are being released from the storage tubules. The same data for wild zebra finches breeding in captivity also showed no significant effect of numbers of birds or eggs on number of spermatozoa (Fig. 1d). The mean clutch size of wild zebra finches was slightly smaller (4.3 eggs $\pm 0.15, n=10$ pairs) than that of domesticated birds
(5.00 $\pm 0.233, n=11$ pairs), a difference that has been recorded in previous studies (Birkhead et al., 1989). However, there were no significant differences between wild and domesticated birds in either the mean number of spermatozoa per clutch (wild: $496.6 \pm 175.3$; domesticated: $404.1 \pm 111.4$ ( $t=0.45$, 19 d.f.)) or the mean numbers of spermatozoa per egg (wild: $119.9 \pm 43.64$; domesticated: $87.4 \pm 28.91(t=0.63,19$ d.f., $t$ tests on log transformed values)).

\section{Numbers of spermatozoa penetrating the perivitelline layer}

A highly significant $(P<0.001)$ relationship was found between the number of spermatozoa attached to, and the Downloaded from Bioscientifica.com at 04/26/2023 09:35:52AM 

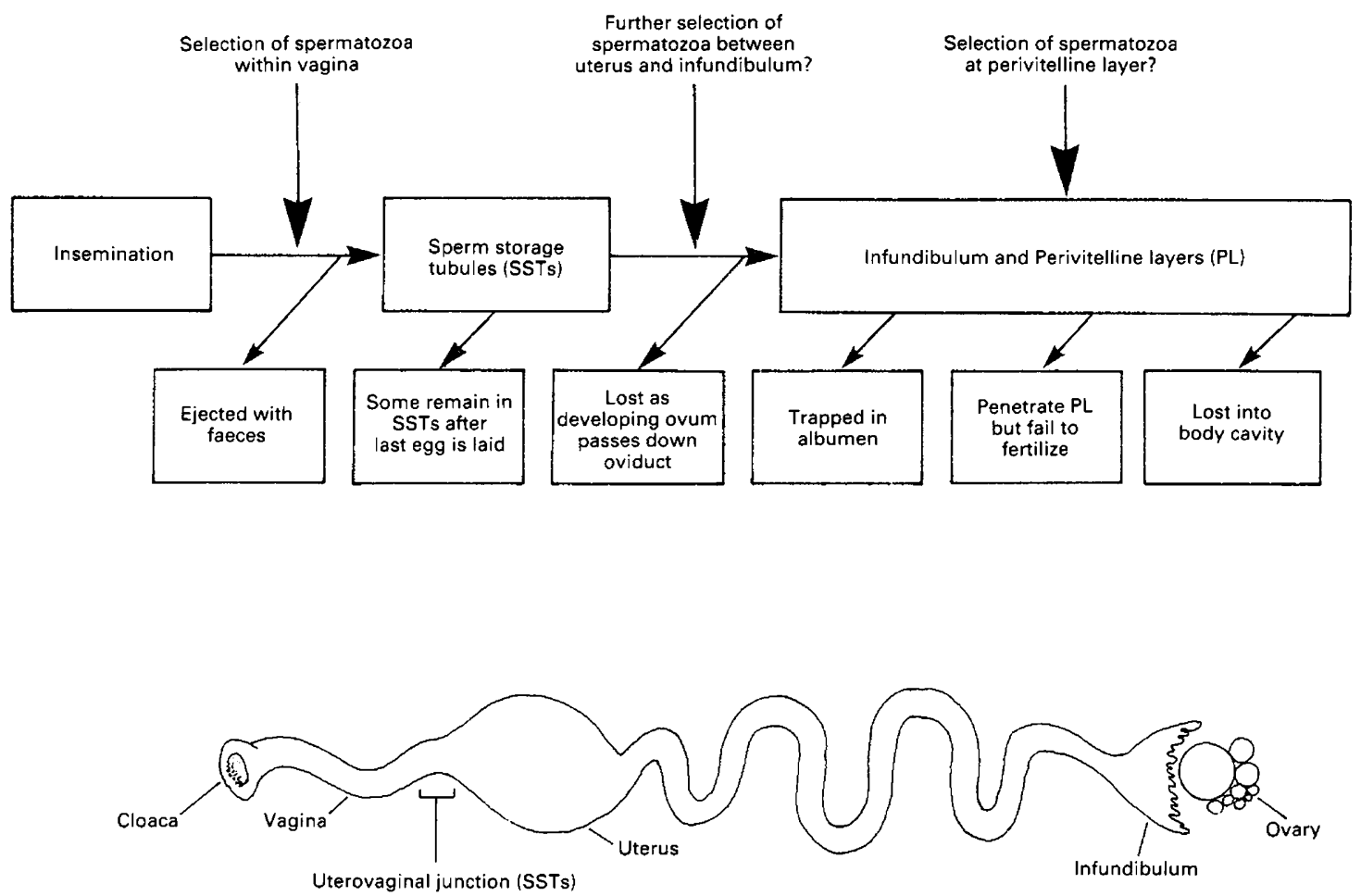

Fig. 4. Schematic diagram to show the various points at which spermatozoa could potentially be lost in the reproductive tract of a female bird. The large boxes show the main events from insemination to spermatozoa reaching the site of fertilization, the infundibulum. The backward pointing arrows show sources of loss. The vertical arrows indicate known and possible processes affecting spermatozoa loss. The lower part of the figure is a diagram of the reproductive tract of the female zebra finch showing the location of the main regions.

number of holes in the perivitelline layer (Fig. 2). The numbers of spermatozoa and holes were closely correlated up to about 100 spermatozoa and 70 holes: but subsequent increases in the number of spermatozoa did not result in a further increase in the number of holes, possibly because the number of spermatozoareceptor sites is limited (see Bakst and Howarth, 1977). Attached spermatozoa, and holes in particular, were concentrated in the vicinity of the germinal disc: the number of holes $\mathrm{mm}^{-2}$ on the germinal disc was $14.68 \pm 2.77$, and away from the germinal disc, $0.14 \pm 0.09(P<0.001$ permutation test for paired data). The number of spermatozoa on the germinal disc $\mathrm{mm}^{-2}$ was $8.761 \pm 2.54$ and away from the germinal disc was $0.957 \pm 0.462(P<0.001)$.

The relationship (Fig. $2 b$ ) was used to estimate the total number of spermatozoa reaching each ovum (i.e. the numbers of spermatozoa trapped on the perivitelline layer plus the numbers penetrating the perivitelline layer). For a single insemination, the mean number of spermatozoa attached to the perivitelline layer was 45.6, and a further 36 penetrated it (total 82). For birds copulating ad libitum, the respective numbers were 404 and 173 (total: 577) for domesticated birds, and 497 and 203 (total 700) for wild birds.

\section{Number of spermatozoa remaining in sperm storage tubules}

All four females that had completed their clutches had some spermatozoa remaining in their sperm storage tubules. The mean percentage of storage tubules containing one or more spermatozoa was $47.7 \pm 15.3 \%$ (range: $4-69 \%$ ). The mean number of spermatozoa per tubule was $2.50 \pm 1.25$ (range: 0.04-5.87), and the estimated total number of spermatozoa (calculated by multiplying the mean numbers per tubule by $1499-$ see above) was $3716 \pm 1881$ (range: 60-8799). The mean percentage of spermatozoa within tubules that were degenerating, having lost their acrosome or with detached flagella (Fig. 3), was $21 \pm 9.9 \%$ (range $4-42 \%$ ). Degenerating spermatozoa have not previously been observed in the sperm storage tubules of female zebra finches examined before the end of egg-laying (Birkhead et al., 1990).

\section{Discussion}

The results of the study reported here show that in zebra finches, a massive reduction in the number of spermatozoa takes place between insemination and storage in the sperm storage tubules, and between the tubules and the infundibulum. On average, $0.104 \%$ of spermatozoa inseminated reach the sperm storage tubules, and, of these, $1.4 \%$ are trapped on or penetrate the perivitelline layers of ova in the infundibulum. The reductions in numbers of spermatozoa between insemination and the sperm storage tubules, and the tubules and the infundibulum rely on different mechanisms. After insemination large numbers of spermatozoa are ejected from the vagina of turkey (Howarth, 
1971) and fowl (Allen and Grigg, 1957). Of the spermatozoa that remain in the vagina, only a small proportion, and only those that are morphologically normal, get into the storage tubules (Bobr et al., 1964). It has been shown that an immunebased selection mechanism within the vagina results in only those spermatozoa with certain surface properties surviving and getting into the tubules (Wishart and Steele, 1990; Steele and Wishart, 1992). Although in the present study only $1.4 \%$ of the spermatozoa in the storage tubules were subsequently detected in the infundibulum, it seems likely that the primary selection site is the vagina and that most of the spermatozoa entering the tubules can fertilize. This is because a relatively large proportion will eventually reach the infundibulum, even if only a small number are trapped on or penetrate the perivitelline layer. Once the release of spermatozoa from the tubules has been initiated, it appears to continue at a more or less constant rate in domestic fowl (Burke and Ogasawara, 1969; Wishart, 1987), turkeys (Bakst, 1981), Japanese quail (Birkhead and Fletcher, in press) and zebra finches (this study).

There are several possible reasons why only a small proportion of the spermatozoa inseminated are trapped on, or penetrate the perivitelline layers. First, as our data show, some spermatozoa remain in the sperm storage tubules after the clutch has been completed. This suggests that the rate at which spermatozoa are lost from the sperm storage tubules is independent of the numbers stored (see Brillard and Antoine, 1990). The fact that after clutch completion spermatozoa deteriorated rapidly in the sperm storage tubules, indicates that the environment in the tubules which maintains spermatozoa intact during the fertile period changes rapidly once egg laying has finished. This has not been observed in poultry, and it seems likely that the ability of females to maintain the integrity of spermatozoa in the sperm storage tubules varies between species. Second, the period during which an ovum is present in the infundibulum and during which fertilization can take place is very brief in domestic fowl and is usually less than I $h$ (Gilbert, 1971). If there is no ovum in the infundibulum, spermatozoa are lost from it into the body cavity (Brillard, 1990). Although some storage of spermatozoa may occur in the infundibulum (Van Drimmelen, 1946; Bobr et al., 1964; Bakst, 1981), storage at this site is short-lived following natural or intravaginal artificial insemination. Third, spermatozoa may be lost from other parts of the oviduct as the developing egg passes down it (Bobr et al., 1964; Kamar and Hafez, 1975; Bakst, 1981). It is also possible that not all spermatozoa present in the infundibulum are trapped on the perivitelline layer; for example, a small proportion may be trapped in the albumen (Bobr et al., 1964), although in the present study no spermatozoa were found in albumen. Fourth, it is possible that active selection of spermatozoa by females continues beyond the vagina and uterovaginal junction, and that some spermatozoa are encouraged or discouraged from reaching the infundibulum (for example, by the speed at which they are transported), or from penetrating the perivitelline layer and fusing with the female nucleus.

The results reported here suggest that a smaller proportion of spermatozoa reaches the site of fertilization in zebra finches than in chickens or turkeys. There could be several reasons for this difference. There could be a difference between natural copulation and artificial insemination. There could be differences in ovum size: the relatively large ovum in birds may require many spermatozoa to ensure fertilization (Briskie and Montgomerie, 1993). (The large difference between the numbers of spermatozoa on the perivitelline layers of zebra finch and chicken and turkey eggs is consistent with this idea.) There could be differences in the reproductive biology of the birds: as Birkhead and Moller (1992b) have shown, the duration of sperm storage in birds varies considerably, and is positively associated with the spread of laying (i.e. clutch size $-1 \times$ the interval between eggs). The rate at which spermatozoa are released from the sperm storage tubules is probably relevant to the number of spermatozoa trapped on the perivitelline layers of ova and the duration of sperm storage (Wishart, 1988). Indeed, there is a negative correlation between median sperm storage duration (from Birkhead, 1988) and the rate of instantaneous loss of spermatozoa (see above) for quail, chickens, turkeys and zebra finches $(r=-0.85)$, although this (statistically nonsignificant) result should be treated with caution because it is based on just four species that do not constitute independent data points. The frequency of insemination may also be important. For example, the wild turkey is a lekbreeding species in which females typically copulate only once, and often several days before the onset of laying (Birkhead and Møller, 1993): sperm storage is protracted in this species so it is not surprising that the rate of spermatozoa release from the sperm storage tubules is much less than that for chickens (Lake and Wishart, 1984; Wishart, 1988), which, in the wild, copulate several times for each clutch (Parker et al., 1940; McBride et al., 1969).

There also appear to be differences between birds and mammals. A greater number of spermatozoa and proportion of the ejaculate reach the site of fertilization in birds than in mammals, although differences in study techniques make direct comparisons difficult. It is possible that this difference is related to the size of eggs of birds, which require large numbers of spermatozoa to ensure fertilization.

The authors thank J. P. Brillard, B. Howarth Jr, P. E. Lake, A. P. Møller, H. Moore and G. J. Wishart for useful discussion or comments on the manuscript. We are grateful to $P$. Young for technical assistance. This research was funded by grants to T. R. Birkhead from SERC and The Royal Society.

\section{References}

Allen TE and Grigg GW (1957) Sperm transport in the fowl Australian Journal of Agricultural Research 8 788-799

Bakst MR (1981) Sperm recovery from oviducts of turkeys at known intervals after insemination and oviposition Joumal of Reproduction and Fertility 62 159-164

Bakst MR and Howarth B Jr (1977) Hydrolysis of the hen's perivitelline layer by cock sperm Biology of Reproduction 17 370-379

Bedford JM (1970) The saga of mammalian sperm from ejaculation to syngamy. In Mammalian Reproduction pp 124-182 Eds H Gibian and EJ Plotz. Springer-Verlag, Berlin.

Birkhead TR (1988) Behavioral aspects of sperm competitions in birds Advances in the Study of Behavior 18 35-72

Birkhead TR (1991) Sperm depletion in the Bengalese finch Lonchura striata Behavioral Ecology 2 267-275

Birkhead TR and Fletcher F (1992) Sperm to spare? Sperm allocation in the zebra finch Animal Behaviour 43 1053-1055

Birkhead TR and Fletcher F Sperm storage and the release of sperm from the sperm storage tubules in Japanese Quail Cotumix japonica Ibis, (in press) 
Birkhead TR and Hunter F (1990a) Mechanisms of sperm competition Trends in Ecology and Evolution 5 48-52

Birkhead TR and Hunter F (1990b) Numbers of sperm-storage tubules in the zebra finch (Peophila guttata) and the Bengalese finch (Lonchura striata) Auk 107 193-197

Birkhead TR and Meller AP (1992a) Sperm Competition in Birds: Evolutionary Causes and Consequences. Academic Press, London

Birkhead TR and Moller AP (1992b) Numbers and size of sperm storage tubules and the duration of sperm storage in birds: a comparative study Biological Joumal of the Linnean Society 45 363-372

Birkhead TR and Meller AP (1993) Why do male birds stop copulating while their partners are still fertile? Animal Behaviour 45 105-118

Birkhead TR, Clarkson K and Zann R (1988) Extra-pair courtship, copulation and mate guarding in wild zebra finches Taeniopygia guttata Animal Behaviour 35 I853-1855

Birkhead TR, Hunter F and Pellatt JE (1989) Sperm competition in the zebra finch, Taeniopygia guttata Animal Behaviour 38 935-950

Birkhead TR, Pellatt JE and Hunter FM (1990) Numbers and distribution of sperm in the uterovaginal sperm storage tubules of the zebra finch Condor 92 508-516

Birkhead TR, Moller AP and Sutherland WJ (1993) Why do females make it so difficult for males to fertilize their eggs? Journal of Theoretical Biology 161 $51-60$

Bobr LW, Lorenz FW and Ogasawara FX (1964) Distribution of spermatozoa in the oviduct and fertility in domestic birds. II. Transport of spermatozoa in the fowl oviduct Journal of Reproduction and Fertility 8 49-58

Bramwell RK and Howarth B (1992) Preferential attachment of cock spermatozoa to the perivitelline layer directly over the germinal disc of the hen's ovum Biology of Reproduction 47 1113-1117

Brillard JP (1990) Migration of spermatozoa in the oviduct of hens following intravaginal, intramagnal and intraabdominal insemination Theriogenology 33 1021-1029

Brillard JP and Antoine $\mathbf{H}$ (1990) Storage of sperm in the uterovaginal junction and its incidence on the numbers of spermatozoa present in the perivitelline layer of hen's eggs British Journal of Poultry Science 31 635-644

Brillard JP and Bakst MR (1990) Quantification of spermatozoa in the sperm storage tubules of turkey hens and its relation to sperm numbers in the perivitelline layer of eggs Biology of Reproduction 43 271-275

Briskie JV and Montgomerie R (1993) Patterns of sperm storage in relation to sperm competition in passerine birds Condor 95 442-454

Burke WH and Ogasawara FX (1969) Presence of spermatozoa in uterovaginal fluids of the hen at various stages of the ovulatory cycle Poultry Science $\mathbf{4 8}$ 408-413

Cheng KMr Burns JT and McKinney F (1983) Forced copulation in captive mallards. III. Sperm competition Auk 100 302-310

Compton MM, Van Krey HP and Siegel PB (1978) The filling and emptying of the uterovaginal sperm-host glands in the domestic hen Poultry Science $\mathbf{5 7}$ $1696-1700$

Gilbert AB (1971) Transport of eggs through the oviduct and oviposition. In Physiology and Biochemistry of the Domestic Fowl pp 1345-1352 Eds DJ Bell and BM Freeman. Academic Press, New York

Ginsberg JR and Huck UW (1989) Sperm competition in mammals Trends in Ecology and Evolution 4 74-79

Howarth B (1971) Transport of spermatozoa in the reproductive tract of turkey hens Poultry Science $\mathbf{5 0} 84$

Johnson AL (1986) Reproduction in the male. In Avian Physiology pp 432-45I Ed. PD Sturkie. Springer Verlag, Amsterdam

Kamar GAR and Hafez ESE (1975) Maturation and transport of avian spermatozoa. In The Biology of Spermatozoa pp 114-122. INSERM Nouzilly

Lake PE and Wishart GJ (1984) Comparative physiology of turkey and fowl semen. In Reproductive Biology of Poultry pp 151-160. Eds FJ Cunningham, PE Lake and D Hewitt. Longman, Harlow
Lessells CM and Birkhead TR (1990) Mechanisms of sperm competition in birds: mathematical models Behavioural Ecology and Sociobiology 27 325-337

McBride G, Parer IP and Foenander F (1969) The social organization and behaviour of the feral domestic fowl. 1. Field studies on Northwest Island Animal Behaviour Monographs 2 127-181

Madsen T, Shine R, Loman J and Hakansson T (1992) Why do female adders copulate so frequently? Nature 355 440-441

Martin PA, Reimers TJ, Lodge JR and Dziuk PJ (1974) The effect of ratios and numbers of spermatozoa mixed from two males on proportions of offspring Journal of Reproduction and Fertility 39 251-258

Moller AP (1988) Testes size, ejaculate quality, and sperm competition in birds Biological Journal of the Linnean Society 33 273-283

Moller AP (1989) Ejaculate quality, testes size and sperm production in mammals Functional Ecology 3 91-96

Moller AP and Birkhead TR (1989) Copulation behaviour of mammals: evidence that sperm competition is widespread Biological Journal of the Linnean Society 38 119-131

Parker GA (1970) Sperm competition and its evolutionary consequences in the insects Biological Reviews 45 525-567

Parker GA, McKenzie FF and Kempster HL (1940) Observations on the sexual behaviour of New Hampshire male Poultry Science 19 191-197

Smith RL (Ed) (1984) Sperm Competition and the Evolution of Animal Mating Systems. Academic Press, London

Sossinka R (1980a) Ovarian development in an opportunistic breeder, the zebra finch Poephila guttata castanotis Joumal of Experimental Biology $211225-230$

Sossinka R (1980b) Reproductive strategies of Estrildid finches in different climate zones of the tropics: gonadal maturation Proceedings of the $17 \mathrm{th}$ Intermational Ornithological Congress Berlin pp 208-215

Sossinka R (1982) Domestication in birds. In Avian Biology pp 373-404 Eds DS Farner, JR King and KC Parkes. Academic Press, London

Steele MG and Wishart GJ (1992) Characterisation of a mechanism impeding sperm transport through the vagina of the chicken Proceedings of the 12th International Congress On Animal Reproduction and A.I. The Hague Vol 3 pp 474-476

Suarez SS, Drost M, Redfern K and Gottlieb W (1990) Sperm motility in the oviduct. In Fertilization in Mammals pp 111-124 Eds BD Bavister, J Cumins and ERS Roldan. Sereno Symposia, Norwell, MS

Taggart DA and Temple-Smith PD (1991) Transport and storage of spermatozoa in the female reproductive tract of the brown marsupial mouse, Antechinus stuartii (Dasyuridae) Joumal of Reproduction and Fertility 93 97-110

Van Drimmelen GC (1946) 'Sperm rests' in the oviduct of the domestic hen Journal of South African Veterinary Medical Association 17 42-52

Van Krey HP (1990) Reproductive biology in relation to breeding and genetics. In Poultry Breeding and Genetics pp 61-90 Ed. RD Crawford. Elsevier, Amsterdam

Wishart GJ (1987) Regulation of the length of the fertile period in the domestic fowl by numbers of oviductal spermatozoa as reflected by those trapped on laid eggs Journal of Reproduction and Fertility $80493-498$

Wishart GJ (1988) Numbers of oviductal spermatozoa and the length of the fertile period in different avian species Proceedings of the 11th International Congress of Animal Reproduction and Artificial Insemination Dublin Vol 3 pp 362-364

Wishart GJ and Steele MG (1990) The influence of sperm surface characteristics on sperm function in the female reproductive tract. In Control of Fertility in Domestic Birds pp 101-112. Ed. JP Brillard. INRA, Paris

Wolfson A (1954) Notes on the cloacal protuberance, seminal vesicles, and a possible copulatory organ in male passerine birds Bulletin of Chicago Academy of Science 10 1-23 